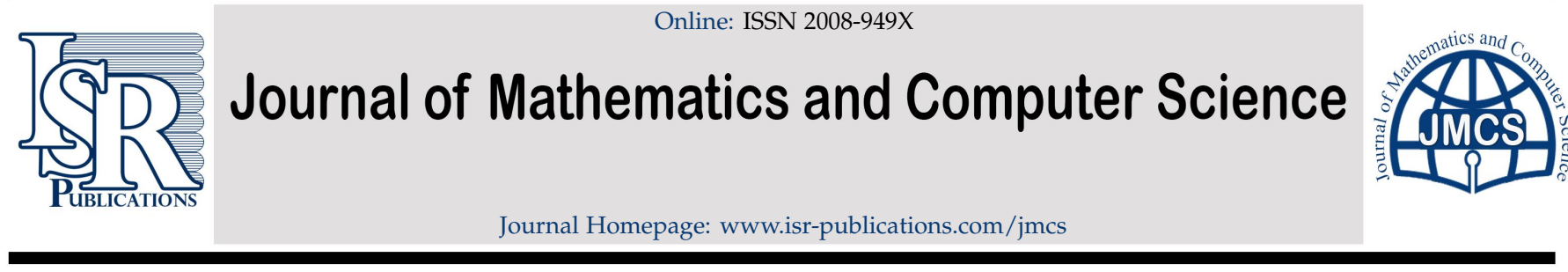

\title{
Some new results of fixed point in dislocated quasi-metric spaces
}

\author{
S. Mhanna ${ }^{a}$, O. Baiz ${ }^{b}$, H. Benaissa ${ }^{c}$, D. El Moutawakil ${ }^{a}$ \\ aUniversity Sultan Moulay Slimane, Equipe de recherche MATIC, FPK, Morocco. \\ ${ }^{b}$ University Ibn Zohr, Lab. Eng. Sci. and Energies, FP of Ouarzazate, Morocco. \\ ${ }^{c}$ University Sultan Moulay Slimane, FP of Khouribga, Morocco.
}

\begin{abstract}
In this paper, we introduce some new fixed point theorems in a dislocated quasi-metric space. We present several fixed point theorems, which generalize and improve some comparable fixed point results. Moreover, we provide some examples to illustrate our results.
\end{abstract}

Keywords: Fixed point, dislocated quasi-metric spaces, contraction mapping.

2020 MSC: 47H10, 54H25, 55M20.

(C)2022 All rights reserved.

\section{Introduction}

The Banach contraction principle in metric space is the first important result in fixed point theory [4]. Since then, various generalizations have been made in many different forms with different types of spaces [1-3] and [5-7, 10-15]. Some of the well-known generalizations, with useful applications in logical programming and electronics engineering [9], are obtained in the framework of dislocated metric spaces [8], and dislocated quasi-metric spaces [15]. The present paper provides new generalizations of fixed point theorem in the setting of dislocated quasi-metric spaces, which generalize, improve, and fuse the results founded in $[2,12-14]$ by using a new contraction type and without any continuity requirement.

\section{Preliminaries}

We introduce here some basic concepts of the theory of dislocated quasi-metric spaces [15].

Definition 2.1. Let $X$ be a nonempty set and $d: X \times X \rightarrow \mathbb{R}^{+}$be a function such that

1. $d(x, y)=d(y, x)=0$ implies $x=y$;

2. $d(x, y) \leqslant d(x, z)+d(z, y)$, for all $x, y, z \in X$.

Then, $\mathrm{d}$ is called dislocated quasi-metric (or simply dq-metric) on $X$.

\footnotetext{
*Corresponding author

Email address: mhanna.soufiane@gmail.com (S. Mhanna)

doi: $10.22436 /$ jmcs.024.01.03
}

Received: 2020-07-22 Revised: 2020-09-30 Accepted: 2020-10-11 
Clearly, for a dq-metric, the self distance of points need not to be zero necessarily and the usual property of symmetry is no longer valid. As example for dq-metric space, we can consider the set $X=[0,1]$ endowed with the following dq-metric

$$
d: X \times X \rightarrow \mathbb{R}^{+}, d(x, y)=|x-y|+|x| .
$$

Definition 2.2. A sequence $\left\{x_{n}\right\}$ in a dq-metric space $(X, d)$ is called a Cauchy sequence if for every $\epsilon>0$, there exists $N \in \mathbb{N}$ such that,

$$
\mathrm{d}\left(x_{\mathrm{m}}, x_{\mathrm{n}}\right) \leqslant \epsilon \text { or } \mathrm{d}\left(\mathrm{x}_{\mathrm{n}}, \mathrm{x}_{\mathrm{m}}\right) \leqslant \epsilon, \quad \forall \mathrm{m}, \mathrm{n} \geqslant \mathrm{N} .
$$

Definition 2.3. A sequence $\left\{x_{n}\right\}$ is said to be dq-convergent to $x$ in a dq-metric space $X$, if

$$
\lim _{n \rightarrow \infty} d\left(x_{n}, x\right)=\lim _{n \rightarrow \infty} d\left(x, x_{n}\right)=0 .
$$

Here, $x$ is called dq-limit of sequence $\left\{x_{n}\right\}$ and we write $x_{n} \rightarrow x$, as $n \rightarrow \infty$.

Definition 2.4. Let $\left(X, d_{1}\right)$ and $\left(Y, d_{2}\right)$ be two dq-metric spaces, the function $f: X \rightarrow Y$ is said to be continuous if for each sequence $\left\{x_{n}\right\} \subset X$ which dq-converges to $x$ in $X$, the sequence $\left\{f\left(x_{n}\right)\right\}$ is dqconverges to $f(x)$ in $Y$.

Definition 2.5. A dq-metric space $(X, d)$ is called complete if every Cauchy sequence in $X$ is dq-convergent.

We remark here that, in dq-metric space, the dq-limit is unique and a Cauchy sequence which processes a dq-convergent subsequence, is also dq-converges. In the sequel, for simplicity, we omit the prefix " $\mathrm{dq}$ " to indicate the limit and convergence.

\section{Main results}

First, we start with the following lemma which we will use in the sequel.

Lemma 3.1. If $x$ is a limit of some sequence $\left\{x_{n}\right\}$ in a dq-metric space $(X, d)$, then

$$
d(x, x)=0 .
$$

Proof. Let $x \in X$, and $\left\{x_{n}\right\} \subset X$ a sequence which converges to $x$. Then

$$
\mathrm{d}(x, x) \leqslant \mathrm{d}\left(x, x_{\mathrm{n}}\right)+\mathrm{d}\left(x_{\mathrm{n}}, x\right), \quad \forall \mathrm{n} \in \mathbb{N} .
$$

Passing to limit, when $n \rightarrow \infty$, we obtain $d(x, x) \leqslant 0$, and therefore

$$
d(x, x)=0 .
$$

Next, we state and prove our main fixed point result in complete dq-metric spaces. Unlike various papers which impose the contraction continuity condition [2], the following result provides the same result without continuity condition and under less restrictive condition.

Theorem 3.2. Let $(\mathrm{X}, \mathrm{d})$ be a complete dq-metric space and $\mathrm{T}$ a self-mapping of $\mathrm{X}$ such that

$$
d(T x, T y) \leqslant \lambda \max \left\{\begin{array}{l}
2 d(x, y), \frac{2 d(x, T x) d(y, T y)}{d(x, y)},[d(x, T x)+d(y, T y)], \\
\frac{[d(x, T y)+d(y, T x)]}{2},[d(x, T x)+d(x, y)], \\
{[d(y, T y)+d(x, y)], \frac{2[d(x, T y)+d(x, y)]}{3}}
\end{array}\right\},
$$

for all $x, y \in X$ with $\mathrm{d}(x, y) \neq 0$, and $\lambda \in\left[0, \frac{1}{2}\right)$. Then, $T$ has a unique fixed point in $\mathrm{X}$. 
Proof. Assume $\mathrm{T}: \mathrm{X} \rightarrow \mathrm{X}$ verifies the condition (3.1), we consider

$$
M(x, y)=\max \left\{\begin{array}{l}
2 d(x, y), \frac{2 d(x, T x) d(y, T y)}{d(x, y)}, d(x, T x)+d(y, T y), \\
\frac{d(x, T y)+d(y, T x)}{2}, d(x, T x)+d(x, y), \\
d(y, T y)+d(x, y), \frac{2[d(x, T y)+d(x, y)]}{3}
\end{array}\right\} .
$$

Then, we distinguish the following different cases.

$\diamond$ Case 1: If $M(x, y)=\frac{2 d(x, T x) d(y, T y)}{d(x, y)}$, then

$$
\mathrm{d}(T x, T y) \leqslant \lambda \frac{2 \mathrm{~d}(x, T x) d(y, T y)}{\mathrm{d}(x, y)}, \quad \forall x, y \in X .
$$

Taking $y=T x$, respectively $x=T y$, in the previous inequality, we find

$$
\begin{aligned}
& d\left(T x, T^{2} x\right) \leqslant 2 \lambda d\left(T x, T^{2} x\right), \quad \forall x \in X, \\
& d\left(T^{2} y, T y\right) \leqslant \lambda \frac{2 d\left(T y, T^{2} y\right) d(y, T y)}{d(T y, y)}, \quad \forall y \in X .
\end{aligned}
$$

Since $2 \lambda \in[0,1)$, the inequality (3.2) implies that $d\left(T x, T^{2} x\right)=0$, for all $x \in X$, which leads also, by taking $y=x$ in the inequality (3.3) to $d\left(T^{2} x, T x\right)=0$, for all $x \in X$. Therefore, we conclude that $T^{2} x=T x$ and thus the mapping $T$ has a fixed point.

$\diamond$ Case 2 : If $M(x, y)=2 d(x, y)$, then

$$
d(T x, T y) \leqslant 2 \lambda d(x, y), \quad \forall x, y \in X
$$

We consider a Picard sequence $x_{n+1}=T x_{n}$ with initial guess $x_{0} \in X$. We will show that $\left\{x_{n}\right\}$ is a Cauchy sequence in $X$. For that, let $n \in \mathbb{N}^{*}$ and use (3.4) to get

$$
d\left(x_{n}, x_{n+1}\right)=d\left(T x_{n-1}, T x_{n}\right) \leqslant 2 \lambda d\left(x_{n-1}, x_{n}\right)=h d\left(x_{n-1}, x_{n}\right) .
$$

We reiterate this process to find $d\left(x_{n}, x_{n+1}\right) \leqslant h^{n} d\left(x_{0}, x_{1}\right)$ and then we conclude

$$
\begin{aligned}
d\left(x_{n}, x_{m}\right) & \leqslant d\left(x_{n}, x_{n+1}\right)+d\left(x_{n+1}, x_{n+2}\right)+\cdots+d\left(x_{m-1}, x_{m}\right) \\
& \leqslant\left(h^{n}+h^{n+1}+\cdots+h^{m-1}\right) d\left(x_{0}, x_{1}\right) \\
& \leqslant \frac{h^{n}}{1-h} d\left(x_{0}, x_{1}\right) .
\end{aligned}
$$

Since $h=2 \lambda \in[0,1)$, it follows from (3.5) that $\left\{x_{n}\right\}$ is a Cauchy sequence in a complete dq-metric space, and therefore there exists $u \in X$ such that

$$
\lim _{n \rightarrow \infty} x_{n}=u \text { and } \lim _{n \rightarrow \infty} T x_{n}=u .
$$

From the inequality (3.4), we deduce

$$
\mathrm{d}\left(T x_{n}, T u\right) \leqslant 2 \lambda d\left(x_{n}, u\right), \quad \forall n \in \mathbb{N} .
$$

Then, since $d(\cdot, T u), d(\cdot, u): X \rightarrow \mathbb{R}$ are continuous, we deduce

$$
d(u, T u)=\lim _{n \rightarrow \infty} d\left(T x_{n}, T u\right) \leqslant 2 \lambda \lim _{n \rightarrow \infty} d\left(x_{n}, u\right)=2 \lambda d(u, u) .
$$

From Lemma 3.1, $d(u, u)=0$ and thus $d(u, T u)=0$. On the other hand, we have

$$
\begin{aligned}
d(T u, u) & \leqslant d\left(T u, x_{n}\right)+d\left(x_{n}, u\right)=d\left(T u, T x_{n-1}\right)+d\left(x_{n}, u\right) \\
& \leqslant 2 \lambda d\left(u, x_{n-1}\right)+d\left(x_{n}, u\right) \underset{n \rightarrow \infty}{\longrightarrow} 0,
\end{aligned}
$$

which leads to $d(T u, u)=0$ and then $d(u, T u)=d(T u, u)=0$. Therefore, we conclude that $T u=u$ and hence $T$ has a fixed point. 
$\diamond$ Case 3: If $M(x, y)=[d(x, T x)+d(y, T y)]$, then

$$
d(T x, T y) \leqslant \lambda[d(x, T x)+d(y, T y)], \quad \forall x, y \in X
$$

We consider a sequence $x_{n+1}=T x_{n}$ with initial guess $x_{0} \in X$. We will prove that $\left\{x_{n}\right\}$ is a Cauchy sequence. For that, we use (3.6) to deduce

$$
\begin{aligned}
d\left(x_{n}, x_{n+1}\right) & =d\left(T x_{n-1}, T x_{n}\right) \\
& \leqslant \lambda\left[d\left(x_{n-1}, T x_{n-1}\right)+d\left(x_{n}, T x_{n}\right)\right] \\
& \leqslant \lambda d\left(x_{n-1}, x_{n}\right)+\lambda d\left(x_{n}, x_{n+1}\right), \quad \text { for } n \in \mathbb{N},
\end{aligned}
$$

which implies

$$
d\left(x_{n}, x_{n+1}\right) \leqslant \frac{\lambda}{1-\lambda} d\left(x_{n-1}, x_{n}\right), \quad \text { for } n \in \mathbb{N} .
$$

Since $h=\frac{\lambda}{1-\lambda} \in[0,1)$, then $\left\{x_{n}\right\}$ is a Cauchy sequence in the complete space $X$, and therefore there exists $u \in X$ such that

$$
\lim _{n \rightarrow \infty} x_{n}=u \text { and } \lim _{n \rightarrow \infty} T x_{n}=u .
$$

Next, to prove that $u$ is the fixed point of $T$, we use (3.6) to obtain

$$
\begin{aligned}
d\left(T x_{n}, T u\right) & \leqslant \lambda\left[d\left(x_{n}, T x_{n}\right)+d(u, T u)\right] \\
& \leqslant \lambda\left[d\left(x_{n}, u\right)+d\left(u, T x_{n}\right)+d(u, T u)\right], \quad \forall n \in \mathbb{N} .
\end{aligned}
$$

Then, by passing to limit for in the above inequality, we find

$$
d(u, T u) \leqslant \frac{2 \lambda}{1-\lambda} d(u, u)
$$

Using Lemma 3.1, we get $d(u, T u)=0$. On the other hand, we have

$$
\begin{aligned}
d(T u, u) & \leqslant d\left(T u, x_{n}\right)+d\left(x_{n}, u\right)=d\left(T u, T x_{n-1}\right)+d\left(x_{n}, u\right) \\
& \leqslant \lambda\left[d(u, T u)+d\left(x_{n-1}, T x_{n-1}\right)\right]+d\left(x_{n}, u\right) \\
& \leqslant \lambda\left[d\left(x_{n-1}, u\right)+d\left(u, T x_{n-1}\right)\right]+d\left(x_{n}, u\right) \\
& =\lambda\left[d\left(x_{n-1}, u\right)+d\left(u, x_{n}\right)\right] d\left(x_{n}, u\right) \underset{n \rightarrow \infty}{\longrightarrow} 0
\end{aligned}
$$

which implies that $d(T u, u)=0$ and then $d(u, T u)=d(T u, u)=0$. Therefore, we conclude that $T u=u$ and hence $T$ has a fixed point.

$\diamond$ Case $4:$ If $M(x, y)=\frac{d(x, T y)+d(y, T x)}{2}$, then

$$
d(T x, T y) \leqslant \frac{\lambda}{2}[d(x, T y)+d(y, T x)], \quad \forall x, y \in X
$$

We consider a sequence $x_{n+1}=T x_{n}$ with initial guess $x_{0} \in X$. Then, we have

$$
\begin{aligned}
d\left(x_{n}, x_{n+1}\right)=d\left(T x_{n-1}, T x_{n}\right) & \leqslant \frac{\lambda}{2}\left[d\left(x_{n-1}, T x_{n}\right)+d\left(x_{n}, T x_{n-1}\right)\right] \\
& \leqslant \frac{\lambda}{2}\left[d\left(x_{n-1}, x_{n+1}\right)+d\left(x_{n}, x_{n}\right)\right] \\
& \leqslant \frac{\lambda}{2}\left[d\left(x_{n-1}, x_{n}\right)+d\left(x_{n}, x_{n+1}\right)+d\left(x_{n}, x_{n}\right)\right]
\end{aligned}
$$


for all $n \in \mathbb{N}^{*}$. Moreover, we have

$$
\begin{aligned}
\mathrm{d}\left(x_{n}, x_{n}\right)=\mathrm{d}\left(T x_{n-1}, T x_{n-1}\right) & \leqslant \frac{\lambda}{2}\left[\mathrm{~d}\left(x_{n-1}, T x_{n-1}\right)+\mathrm{d}\left(x_{n-1}, T x_{n-1}\right)\right] \\
& =\lambda d\left(x_{n-1}, x_{n}\right) \\
& \leqslant d\left(x_{n-1}, x_{n}\right), \quad \forall n \in \mathbb{N}^{*} .
\end{aligned}
$$

Then, we combine the two inequalities (3.8) and (3.9) to find

$$
\begin{aligned}
d\left(x_{n}, x_{n+1}\right) & \leqslant \frac{\lambda}{2}\left[d\left(x_{n-1}, x_{n}\right)+d\left(x_{n}, x_{n+1}\right)+d\left(x_{n-1}, x_{n}\right)\right] \\
& =\frac{\lambda}{2}\left[2 d\left(x_{n-1}, x_{n}\right)+d\left(x_{n}, x_{n+1}\right)\right], \quad \forall n \in \mathbb{N}^{*} .
\end{aligned}
$$

Next, this inequality can be reformulated as follows

$$
\mathrm{d}\left(\mathrm{x}_{\mathrm{n}}, \mathrm{x}_{\mathrm{n}+1}\right) \leqslant \frac{\lambda}{1-\frac{\lambda}{2}} \mathrm{~d}\left(\mathrm{x}_{\mathrm{n}-1}, \mathrm{x}_{\mathrm{n}}\right), \quad \forall \mathrm{n} \in \mathbb{N}^{*}
$$

We can easily see that $h=\frac{\lambda}{1-\frac{\lambda}{2}} \in[0,1)$, and then $\left\{x_{n}\right\}$ is a Cauchy sequence in the complete space $X$. Therefore, there exists $u \in X$ such that

$$
\lim _{n \rightarrow \infty} x_{n}=u \text { and } \lim _{n \rightarrow \infty} T x_{n}=u .
$$

From the inequality (3.7), we deduce

$$
\mathrm{d}\left(T x_{n}, T u\right) \leqslant \frac{\lambda}{2}\left[d\left(x_{n}, T u\right)+d\left(u, T x_{n}\right)\right], \quad \forall n \in \mathbb{N}^{*} .
$$

Passing to limit, as $n \rightarrow \infty$, we obtain

$$
d(u, T u) \leqslant \frac{\lambda}{2}[d(u, T u)+d(u, u)] .
$$

Using Lemma 3.1, it follows from (3.10) that

$$
d(u, T u) \leqslant \frac{\lambda}{2} d(u, T u)
$$

which implies that $d(u, T u)=0$, since $\frac{\lambda}{2} \in[0,1)$. On the other hand, we have

$$
\begin{aligned}
d(T u, u) & \leqslant d\left(T u, x_{n}\right)+d\left(x_{n}, u\right)=d\left(T u, T x_{n-1}\right)+d\left(x_{n}, u\right) \\
& \leqslant \frac{\lambda}{2}\left[d\left(u, T x_{n-1}\right)+d\left(x_{n-1}, T u\right)\right]+d\left(x_{n}, u\right) \\
& \leqslant \frac{\lambda}{2}\left[d\left(u, x_{n}\right)+d\left(x_{n-1}, u\right)+d(u, T u)\right]+d\left(x_{n}, u\right) \\
& =\frac{\lambda}{2}\left[d\left(u, x_{n}\right)+d\left(x_{n-1}, u\right)\right]+d\left(x_{n}, u\right) \underset{n \rightarrow \infty}{\longrightarrow} 0
\end{aligned}
$$

which implies that $d(T u, u)=0$ and then $d(u, T u)=d(T u, u)=0$. Therefore, we conclude that $T u=u$ and hence $\mathrm{T}$ has a fixed point.

$\diamond$ Case 5 : If $M(x, y)=d(x, T x)+d(x, y)$, then

$$
d(T x, T y) \leqslant \lambda[d(x, T x)+d(x, y)], \quad \forall x, y \in X .
$$


We define a sequence $x_{n+1}=T x_{n}$ with initial guess $x_{0} \in X$. Then, we have

$$
\begin{aligned}
d\left(x_{n}, x_{n+1}\right)=d\left(T x_{n-1}, T x_{n}\right) & \leqslant \lambda\left[d\left(x_{n-1}, T x_{n-1}\right)+d\left(x_{n-1}, x_{n}\right)\right] \\
& =\lambda\left[d\left(x_{n-1}, x_{n}\right)+d\left(x_{n-1}, x_{n}\right)\right] \\
& =2 \lambda d\left(x_{n-1}, x_{n}\right), \quad \forall n \in \mathbb{N}^{*} .
\end{aligned}
$$

Since $2 \lambda \in[0,1),\left\{x_{n}\right\}$ is a Cauchy sequence in the complete space $X$. Then, there exists $u \in X$ such that $\left\{x_{n}\right\}$ and $\left\{T x_{n}\right\}$ converge to $u$ in $X$. Next, for all $n \in \mathbb{N}^{*}$, we have

$$
\begin{aligned}
d\left(T x_{n}, T u\right) & \leqslant \lambda\left[d\left(x_{n}, T x_{n}\right)+d\left(x_{n}, u\right)\right] \\
& \leqslant \lambda\left[d\left(x_{n}, u\right)+d\left(u, T x_{n}\right)+d\left(x_{n}, u\right)\right], \\
d\left(T u, T x_{n}\right) & \leqslant \lambda\left[d(u, T u)+d\left(u, x_{n}\right)\right] .
\end{aligned}
$$

We pass to limit in (3.11) to get $d(u, T u)=0$ and then in (3.12) to conclude

$$
d(u, T u)=d(T u, u)=0 .
$$

Therefore, we have $T u=u$ and thus $u$ is a fixed point of $T$.

$\diamond$ Case 6: If $M(x, y)=d(y, T y)+d(x, y)$, then

$$
d(T x, T y) \leqslant \lambda[d(y, T y)+d(x, y)], \quad \forall x, y \in X .
$$

We consider a sequence $x_{n+1}=T x_{n}$ with a given $x_{0} \in X$. Then, we have

$$
\begin{aligned}
d\left(x_{n}, x_{n+1}\right)=d\left(T x_{n-1}, T x_{n}\right) & \leqslant \lambda\left[d\left(x_{n}, T x_{n}\right)+d\left(x_{n-1}, x_{n}\right)\right] \\
& \leqslant \lambda\left[d\left(x_{n}, x_{n+1}\right)+d\left(x_{n-1}, x_{n}\right)\right]
\end{aligned}
$$

for all $n \in \mathbb{N}^{*}$. Then, for $h=\frac{\lambda}{1-\lambda} \in[0,1)$, we conclude that

$$
\mathrm{d}\left(\mathrm{x}_{\mathrm{n}}, \mathrm{x}_{\mathrm{n}+1}\right) \leqslant \mathrm{hd}\left(\mathrm{x}_{\mathrm{n}-1}, \mathrm{x}_{\mathrm{n}}\right), \quad \forall \mathrm{n} \in \mathbb{N}^{*} .
$$

Therefore, $\left\{x_{n}\right\}$ is a Cauchy sequence in the complete space $X$, and then there exists $u \in X$ such that $\left\{x_{n}\right\}$ and $\left\{T x_{n}\right\}$ converge to $u$ in $X$. Furthermore, we have

$$
\begin{aligned}
d\left(T u, T x_{n}\right) & \leqslant \lambda\left[d\left(x_{n}, T x_{n}\right)+d\left(u, x_{n}\right)\right] \\
& \leqslant \lambda\left[d\left(x_{n}, u\right)+d\left(u, T x_{n}\right)+d\left(u, x_{n}\right)\right], \\
d\left(T x_{n}, T u\right) & \leqslant \lambda\left[d(u, T u)+d\left(x_{n}, u\right)\right] .
\end{aligned}
$$

We pass to limit in (3.13) to get $d(T u, u)=0$, and then in (3.14) to conclude

$$
d(u, T u) \leqslant \lambda d(u, T u) .
$$

Therefore, since $\lambda \in[0,1)$, we deduce that $d(u, T u)=0$. Finally, we conclude that

$$
d(T u, u)=d(u, T u)=0,
$$

which leads to $T u=u$ and thus the self-mapping $T$ has a fixed point $u$.

$\diamond$ Case $7:$ If $M(x, y)=\frac{2}{3}[d(x, T y)+d(x, y)]$, then

$$
d(T x, T y) \leqslant \frac{2 \lambda}{3}[d(x, T y)+d(x, y)], \quad \forall x, y \in X
$$


Let $x_{0} \in X$ given, we consider a sequence $x_{n+1}=T x_{n}$, then from (3.15), it follows

$$
\begin{aligned}
d\left(x_{n}, x_{n+1}\right) & =d\left(T x_{n-1}, T x_{n}\right) \\
& \leqslant \frac{2 \lambda}{3}\left[d\left(x_{n-1}, T x_{n}\right)+d\left(x_{n-1}, x_{n}\right)\right] \\
& =\frac{2 \lambda}{3}\left[d\left(x_{n-1}, x_{n+1}\right)+d\left(x_{n-1}, x_{n}\right)\right] \\
& \leqslant \frac{2 \lambda}{3}\left[d\left(x_{n-1}, x_{n}\right)+d\left(x_{n}, x_{n+1}\right)+d\left(x_{n-1}, x_{n}\right)\right]
\end{aligned}
$$

for all $x, y \in X$ and $n \in \mathbb{N}^{*}$. This inequality implies that

$$
\mathrm{d}\left(x_{n}, x_{n+1}\right) \leqslant \frac{\frac{4 \lambda}{3}}{1-\frac{2 \lambda}{3}} \mathrm{~d}\left(x_{n-1}, x_{n}\right), \quad \forall x, y \in X
$$

Since $h=\frac{\frac{4 \lambda}{3}}{1-\frac{2 \lambda}{3}} \in[0,1)$, the inequality (3.16) implies that $\left\{x_{n}\right\}$ is a Cauchy sequence in the complete space $X$. Therefore, there exists $u \in X$ such that,

$$
\lim _{n \rightarrow \infty} x_{n}=u \text { and } \lim _{n \rightarrow \infty} T x_{n}=u \text {. }
$$

Thus, the continuity of $d(\cdot, u), d(\cdot, T u): X \rightarrow \mathbb{R}$ and (3.15) lead to

$$
\begin{aligned}
d(u, T u) & =\lim _{n \rightarrow \infty} d\left(T x_{n}, T u\right) \\
& \leqslant \lim _{n \rightarrow \infty} \frac{2 \lambda}{3}\left[d\left(x_{n}, T u\right)+d\left(x_{n}, u\right)\right]=\frac{2 \lambda}{3} d(u, T u),
\end{aligned}
$$

which implies that $d(u, T u)=0$, since $\frac{2 \lambda}{3} \in[0,1)$. Moreover, we have

$$
d\left(T u, T x_{n}\right) \leqslant \frac{2 \lambda}{3}\left[d\left(u, T x_{n}\right)+d\left(u, x_{n}\right)\right] .
$$

Keeping in mind (3.17), we deduce that $d(T u, u)=0$ and finally, we conclude that

$$
d(u, T u)=d(T u, u)=0,
$$

which implies that $T u=u$, and hence $u$ is a fixed point of $T$. Therefore, the existence part of Theorem 3.2 has been established. For the uniqueness part, we consider two fixed points $u, v \in X$ of a self-mapping $T$ where $u$ is the unique limit of the Picard sequence $x_{n+1}=T x_{n}$ with a given initial guess $x_{0} \in X$. Then, it comes from (3.1) that

$$
d(T u, T v) \leqslant \lambda \max \left\{\begin{array}{l}
2 \mathrm{~d}(u, v), \frac{2 d(u, T u) d(v, T v)}{d(u, v)}, d(u, T u)+d(v, T v), \\
\frac{d(u, T v)+d(v, T u)}{2}, d(u, T u)+d(u, v), \\
d(v, T v)+d(u, v), \frac{2[d(u, T v)+d(u, v)]}{3}
\end{array}\right\},
$$

Using Lemma 3.1 and the fact $\lambda \in[0,1 / 2)$, we deduce the following results.

$\diamond$ Case 1: Recalling that $1-2 \lambda>0$, then we have

$$
\begin{aligned}
d(u, v)=d(T u, T v) \leqslant 2 \lambda d(u, v) & \Rightarrow(1-2 \lambda) d(u, v) \leqslant 0 \\
& \Rightarrow d(u, v)=0 .
\end{aligned}
$$

$\diamond$ Case 2: Keeping in mind that $d(u, u)=0$, then we have

$$
\begin{aligned}
d(u, v)=d(T u, T v) & \leqslant \frac{2 \lambda d(u, T u) d(v, T v)}{d(u, v)}=\frac{2 \lambda d(u, u) d(v, v)}{d(u, v)}=0 \\
& \Rightarrow d(u, v)=0 .
\end{aligned}
$$


$\diamond$ Case 3: Keeping in mind that $d(u, u)=0$ and $1-\lambda>0$, then we have

$$
\begin{aligned}
d(u, v)=d(T u, T v) & \leqslant \lambda[d(u, T u)+d(v, T v)]=\lambda[d(u, u)+d(u, v)]=0 \\
& \Rightarrow(1-\lambda) d(u, v) \leqslant 0 \\
& \Rightarrow d(u, v)=0
\end{aligned}
$$

$\diamond$ Case 4 : Recalling that $\frac{\lambda / 2}{1-\lambda / 2} \in[0,1)$, then we have

$$
\begin{aligned}
d(u, v)=d(T u, T v) & \leqslant \lambda \frac{d(u, T v)+d(v, T u)}{2}=\lambda \frac{d(u, v)+d(v, u)}{2} \\
& \Rightarrow d(u, v) \leqslant \frac{\lambda / 2}{1-\lambda / 2} d(v, u) \\
& \Rightarrow d(u, v) \leqslant\left(\frac{\lambda / 2}{1-\lambda / 2}\right)^{2} d(u, v) \\
& \Rightarrow d(u, v)=0
\end{aligned}
$$

$\diamond$ Case 5 : Since $d(u, u)=0$ and $1-\lambda>0$, then we have

$$
\begin{aligned}
d(u, v)=d(T u, T v) & \leqslant \lambda[d(u, T u)+d(u, v)]=\lambda[d(u, u)+d(u, v)] \\
& \Rightarrow(1-\lambda) d(u, v) \leqslant 0 \\
& \Rightarrow d(u, v)=0
\end{aligned}
$$

$\diamond$ Case 6: Recalling that $\frac{\lambda}{1-2 \lambda} \in[0,1)$, then we have

$$
\begin{aligned}
d(u, v)=d(T u, T v) & \leqslant \lambda[d(v, T v)+d(u, v)]=\lambda[d(v, v)+d(u, v)] \\
& \leqslant \lambda[d(v, u)+d(u, v)+d(u, v)] \\
& \Rightarrow d(u, v) \leqslant \frac{\lambda}{1-2 \lambda} d(v, u) \\
& \Rightarrow d(u, v) \leqslant\left(\frac{\lambda}{1-2 \lambda}\right)^{2} d(u, v) \\
& \Rightarrow d(u, v)=0 .
\end{aligned}
$$

$\diamond$ Case 7 : Keeping in mind that $1-\frac{4 \lambda}{3}>0$, then we have

$$
\begin{aligned}
d(u, v)=d(T u, T v) & \leqslant \frac{2 \lambda}{3}[d(u, T v)+d(u, v)]=\frac{2 \lambda}{3}[d(u, v)+d(u, v)] \\
& \Rightarrow\left(1-\frac{4 \lambda}{3}\right) d(u, v) \leqslant 0 \\
& \Rightarrow d(u, v)=0 .
\end{aligned}
$$

Hence, we have proved that in all the cases, that $d(u, v)=0$. In addition, by using the same techniques, we can show that $d(v, u)=0$, and therefore, we can conclude that $u=v$.

Now, we illustrate our result by the following example.

Example 3.3. Consider the set $X=\left\{0,10, \frac{1}{5}\right\}$ endowed with the metric $d$ defined by

$$
\mathrm{d}(x, y)=x+2 y, \quad \forall x, y \in X .
$$

We construct a self-mapping $\mathrm{T}$ by $\mathrm{T}(0)=0, \mathrm{~T}(10)=\frac{1}{5}$ and $\mathrm{T}\left(\frac{1}{5}\right)=0$. For $\lambda=\frac{1}{3}$, we can easily see that all the assumptions of Theorem 3.2 are satisfied, and then 0 is the unique fixed point of a mapping $T$. 
As a consequence of Theorem 3.2, we may state the following corollary.

Corollary 3.4 ([12, Theorem 3.1]). Let $(X, \mathrm{~d})$ be a complete dq-metric space and $\mathrm{T}: \mathrm{X} \rightarrow \mathrm{X}$ a continuous selfmapping. If the following condition holds

$$
\begin{aligned}
d(T x, T y) \leqslant & a_{1} d(x, y)+a_{2} \frac{d(x, T x) d(y, T y)}{d(x, y)}+a_{3}[d(x, T x)+d(y, T y)] \\
& +a_{4}[d(x, T y)+d(y, T x)]+a_{5}[d(x, T x)+d(x, y)] \\
& +a_{6}[d(y, T y)+d(x, y)]+a_{7}[d(x, T y)+d(y, T x)]
\end{aligned}
$$

for all $x, y \in X$ with $d(x, y) \neq 0$, and where $\left\{a_{i}\right\}_{i=1, \cdots, 7} \subset \mathbb{R}^{+}$satisfying

$$
0<a_{1}+a_{2}+2 a_{3}+4 a_{4}+2 a_{5}+2 a_{6}+3 a_{7}<1,
$$

then, the self-mapping $\mathrm{T}$ has a unique fixed point.

Note here that the above corollary requires continuity of a mapping T. In the next theorem, we provide a comparable result without any the continuity condition.

Theorem 3.5. Let $(\mathrm{X}, \mathrm{d})$ be a complete dq-metric space and $\mathrm{T}: \mathrm{X} \rightarrow \mathrm{X}$ a self-mapping. If

$$
\begin{aligned}
d(T x, T y) \leqslant & a_{1} d(x, y)+a_{2} \frac{d(x, T x) d(y, T y)}{d(x, y)}+a_{3}[d(x, T x)+d(y, T y)] \\
& +a_{4}[d(x, T y)+d(y, T x)]+a_{5}[d(x, T x)+d(x, y)] \\
& +a_{6}[d(y, T y)+d(x, y)]+a_{7}[d(x, T y)+d(y, T x)]
\end{aligned}
$$

holds for all $x, y \in X$ with $\mathrm{d}(x, y) \neq 0$, and where $\left\{a_{i}\right\}_{i=1, \cdots, 7} \subset \mathbb{R}^{+}$satisfying

$$
0<a_{1}+a_{2}+2 a_{3}+4 a_{4}+2 a_{5}+2 a_{6}+3 a_{7}<1,
$$

then, the self-mapping $\mathrm{T}$ has a unique fixed point.

Proof. Let $\mathrm{T}$ be self-mapping of $\mathrm{X}$ verifying assumptions of Theorem 3.5 and consider

$$
M(x, y)=\max \left\{\begin{array}{l}
2 d(x, y), \frac{2 d(x, T x) d(y, T y)}{d(x, y)}, d(x, T x)+d(y, T y), \\
\frac{d(x, T y)+d(y, T x)}{2}, d(x, T x)+d(x, y), \\
d(y, T y)+d(x, y), \frac{2[d(x, T y)+d(y, T x)]}{3}
\end{array}\right\} .
$$

Using the inequality (3.18) and the definition (3.19) of $M$, we find

$$
\begin{aligned}
d(T x, T y) \leqslant & \frac{a_{1}}{2} M(x, y)+\frac{a_{2}}{2} M(x, y)+a_{3} M(x, y) \\
& +2 a_{4} M(x, y)+a_{5} M(x, y)+a_{6} M(x, y)+\frac{3 a_{7}}{2} M(x, y) \\
\leqslant & \left(\frac{a_{1}}{2}+\frac{a_{2}}{2}+a_{3}+2 a_{4}+a_{5}+a_{6}+\frac{3 a_{7}}{2}\right) M(x, y) .
\end{aligned}
$$

We set $\lambda=\frac{a_{1}}{2}+\frac{a_{2}}{2}+a_{3}+2 a_{4}+a_{5}+a_{6}+\frac{3 a_{7}}{2} \in\left[0, \frac{1}{2}\right)$, then, the previous inequality implies

$$
d(T x, T y) \leqslant \lambda M(x, y), \text { with } \lambda \in[0,1) .
$$

Hence, Theorem 3.2 concludes the proof of Theorem 3.5. 
We now provide another result, which generalizes our main result stated Theorem 3.2.

Theorem 3.6. Let $(\mathrm{X}, \mathrm{d})$ be a complete dq-metric space and $\mathrm{T}$ a self-mapping of $\mathrm{X}$ such that

$$
d(T x, T y) \leqslant \lambda \max \left\{\begin{array}{l}
\alpha d(x, y), \frac{\alpha d(x, T x) d(y, T y)}{d(x, y)}, d(x, T x)+d(y, T y), \\
\frac{d(x, T y)+d(y, T x)}{\alpha}, d(x, T x)+d(x, y), \\
d(y, T y)+d(x, y), \frac{\alpha[d(x, T y)+d(y, T x)]}{3}
\end{array}\right\},
$$

for all $x, y \in X$ with $\mathrm{d}(x, y) \neq 0, \lambda \in\left[0, \frac{1}{\alpha}\right)$ and $\alpha \geqslant 2$. Then, $T$ has a unique fixed point in $\mathrm{X}$.

Proof. Theorem 3.6 can be proved in a similar way to the proof of Theorem 3.2.

Here, an illustrative example for which our main result Theorem 3.6 is applicable.

Example 3.7. Consider the set $X=\left\{0, \frac{1}{7}, 30\right\}$ endowed with the following dq-metric

$$
\mathrm{d}(x, y)=x+2 y, \quad \forall x, y \in X .
$$

Next, we construct a self-mapping $\mathrm{T}$ given by $\mathrm{T}(0)=0, \mathrm{~T}(30)=\frac{1}{7}$ and $\mathrm{T}\left(\frac{1}{7}\right)=0$. For $\lambda=\frac{1}{3}$ and $\alpha=3$, we can see that all the assumptions of Theorem 3.6 are satisfied, and hence 0 is the unique fixed point of the mapping $\mathrm{T}$.

\section{Conclusion}

In this paper, we gave some new results of fixed point theorems in complete dislocated quasi-metric space. These results generalize the results founded in [12]. However, their proof of their results seems not to be correct, see page 4698. More precisely, the authors have considered the inequality

$$
\mathrm{d}\left(\xi_{n}, \xi_{n}\right) \leqslant \mathrm{d}\left(\xi_{n-1}, \xi_{n}\right)+\mathrm{d}\left(\xi_{n}, \xi_{n+1}\right)
$$

which is not always true in dq-metric spaces. As example, we consider the set $X=\{0,1,2\}$ and the mapping $d: X \times X \rightarrow \mathbb{R}^{+}$defined by

$$
\begin{aligned}
& d(0,0)=0, d(1,1)=7, d(2,2)=6 \text {, } \\
& d(0,1)=5, d(1,0)=2, d(1,2)=3 \text {, } \\
& d(2,1)=4, d(0,2)=1, d(2,0)=5 \text {. }
\end{aligned}
$$

We can easily verify that $d$ is a dq-metric on $X$ for which the previous inequality is not always valid, as we can see for $\xi_{n-1}=2, \xi_{n}=1$ and $\xi_{n+1}=0$.

\section{Acknowledgment}

The authors are grateful to the editor and anonymous reviewers for their valuable comments.

\section{References}

[1] C. T. Aage, J. N. Salunke, The results on fixed points in dislocated and dislocated quasi-metric space, Appl. Math. Sci., 2 (2008), 2941-2948. 1

[2] C. T. Aage, J. N. Salunke, Some results of fixed point theorem in dislocated quasi-metric spaces, Bull. Marathadawa Math. Soc., 9 (2008), 1-5. 1, 3

[3] M. A. Ahmed, F. M. Zeyada, G. F. Hasan, Fixed point theorems in generalized types of dislocated metric spaces and its applications, Thai J. Math., 11 (2013), 67-73. 1 
[4] S. Banach, Sur les opérateurs dans les ensembles abstraits et leur application aux équations intégrales, Fund. Math., 3 (1992), 133-181. 1

[5] S. Czerwik, Contraction mappings in b-metric spaces, Acta Math. Inform. Univ. Ostrav., 1 (1993), 5-11. 1

[6] T. Dominguez Benavides, M. A. Khamsi, S. Samadi, Uniformly Lipschitzian mappings in modular function spaces, Nonlinear Anal., 46 (2001), 267-278.

[7] A. Hajji, E. Hanebaly, Fixed point theorem and its application to perturbed integral equations in modular function spaces, Electron. J. Differ. Equ., 2005 (2005), 1-11. 1

[8] P. Hitzler, A. K. Seda, Dislocated topologies, J. Electr. Eng., 51 (2000), 3-7. 1

[9] P. Hitzler, Generalized metrics and topology in logic programming semantics, Ph. D Thesis, School of Mathematics, Applied Mathematics and Statistics, National University Ireland, University college Cork, (2001). 1

[10] E. Karapınar, D. O’Regan, A. Roldán López de Hierro, N. Shahzad, Fixed point theorems in new generalized metric spaces, J. Fixed Point Theory Appl., 18 (2016), 645-671. 1

[11] E. Karapınar, P. Salimi, Dislocated metric space to metric spaces with some fixed point theorems, Fixed Point Theory Appl., 2013 (2013), 19 pages.

[12] S. Li, A. Zada, R. Shah, T. Li, Fixed point theorems in dislocated quasi-metric spaces, J. Nonlinear Sci. Appl., 10 (2017), 4695-4703. 1, 3.4, 4

[13] S. T. Patel, M. Patel, Some results of fixed point theorem in dislocated quasi metric space, Int. J. Res. Mod. Eng. Technol., 1 (2013), 20-24.

[14] M. Sarwar, M. U. Rahman, G. Ali, Some fixed point results in dislocated quasi metric (dq-metric) spaces, J. Inequal. Appl., 2014 (2014), 11 pages. 1

[15] F. M. Zeyada, G. H. Hassan, M. A. Ahmed, A generalisations of a fixed point theorem due to Hitzler and Seda in dislocated quasi-metric spaces, Arab. J. Sci. Eng., 31 (2006), 111-114. 1, 2 